\title{
LOS INTÉRPRETES EN FILIPINAS (SIGLOS XVI Y XVII)
}

\author{
Juan Gil Fernández \\ Universidad de Sevilla - Real Academia Española \\ gilvarela@hotmail.com
}

\section{RESUMEN}

Este trabajo recoge y analiza el oficio de intérprete en las islas Filipinas durante los siglos XVI y XVII en textos del Archivo General de Indias.

Palabras Clave: Filipinas, intérpretes, Archivo General de Indias.

INTERPRETERS IN THE PHILIPPINES (16TH AND 17TH CENTURIES)

\section{ABSTRACT}

This paper collects and analyzes the profession of interpreter in the Philippine Islands during the $16^{\text {th }}$ and $17^{\text {th }}$ centuries in texts from the General Archive of the Indies.

KEYwORDs: Philippines, interpreters, General Archive of the Indies.

El oficio de intérprete tardó mucho tiempo en tener un reconocimiento oficial. En los primeros viajes que hicieron por el Pacífico, los españoles llevaron intérpretes, sí, pero sin aceptarlos como tales en el rol. Como se puede ver en otros trabajos míos, los truchimanes recibieron salario como marineros: de marinero sentó plaza Enrique de Malaca, en la primera circunnavegación, o Tristán de la China, en el viaje de Jofré de Loaysa: igual puesto tuvo Luis de Torres, que fue en 1492 con Colón porque «sabía... ebraico y caldeo y aun algo arávigo» (Colón, 1992: 130 doc. 1, 2 nov.).

Cambió la situación en teoría cuando Felipe II ordenó que «los que fueren a descubrir por mar y tierra procuren llevar algunos indios e intérpretes de las partes donde fueren más a propósito» (Recop., 1681: II 81, libro IV título 1º, ley 9).

\section{INTÉRPRETES DURANTE EL VIAJE DE LEGAZPI}

Sin embargo, las cosas no variaron mucho en la práctica durante el asentamiento definitivo en Filipinas (1564). Hizo las funciones de intérprete el agustino Andrés de Urdaneta, auxiliado por otro «lengua» llamado Jerónimo Pacheco. Urdaneta, prior de los frailes que fueron con Legazpi, había estado algunos años en el Maluco, 
luego conocía la lengua malaya; en cuanto a este Jerónimo Pacheco, no disponemos de mucha información. Es probable, por tanto, que el único intérprete «oficial» fuese Pacheco; el agustino iba en la armada como religioso antes que como truchimán.

Los textos son muy elocuentes sobre la constante participación de Urdaneta y Pacheco en las conversaciones con los indígenas:

-15 de febrero de 1565. El alférez Andrés de Ibarra tomó posesión de la isla de Cibabao, siendo testigo Urdaneta, probablemente por la presencia de isleños (Patron. 23: r. 18).

-15 de abril de 1565. En la isla de Bohol los españoles rindieron un bergantín de moros borneos, «los quales, traýdos ante su señoría [Legazpi] y preguntados por lengua del padre prior [Urdaneta]... dixeron» (Patron. 23: r. 17, f. 13r).

-6 de marzo de 1565. Legazpi hizo paces el 5 de mayo en la isla de Abiyo [escrito otras veces Abuyo], «a vista del puerto de Cavalián», con Camutrian, hijo de Maletic, principal del dicho pueblo. En vista de que no traían víveres, «mandó a Gerónimo, naguatato, que en lengua malaya y en la de Maluco dixese a muchos indios que paresçían en la playa que truxesen los dichos bastimentos». El mismo Jerónimo fue en un batel a tierra a hacer el mismo requerimiento por tres veces (Patron. 23: f. 24r).

Legazpi hizo una información en Bohol sobre los desmanes cometidos en dicha isla por los portugueses que estaban en el Maluco (Patron. 23, r. 17). Señalo a continuación los nombres de los testigos y del intérprete:

-25 de marzo de 1565. Testigo: Xicatuna, principal de Bohol. Intérpretes: «Por lengua del padre prior fray Andrés de Hurdaneta, que hablaba en la lengua malaya, e de Tuaçán Malea, natural de la isla de /15r/ de Borneo, que entendía y ablaua la dicha lengua malaya y la d'estas islas Felepinas» (Patron. 23: f. 14v-15r).

-2 de abril. Testigo: Magut, moro indio, natural de Borneo. Intérprete: Urdaneta (Patron. 23: f.15v).

-2 de abril. Testigo: Çeylán, natural de Borneo. Intérprete: Urdaneta (Patron. 23: f. 16v). -22 de abril. Testigos: Bumanglan y Ximongoi, indios naturales de Bohol. Intérpretes: «por lengua del dicho Gerónimo Pacheco, intérprete de la lengua malaya, y de Magut, moro borneo, que entendía la dicha lengua malaya y la de estas islas Felipinas" (Patron. 23: f. 17r.).

-14 de mayo. Testigo: Jerónimo Monzón «oyó decir a los moros borneos por lengua de los intérpretes por lengua de los moros borneos» (Patron. 23: f. 22r).

-27 de abril. En Cebú se habló con los indios «en lengua malaya, siendo intérprete Gerónimo Pacheco, lengua», que desembarcó con el maestre de campo. Siguió haciendo de truchimán también en los requerimientos (Patron. 23: f. 32r, 33r, 33v, 34r). -2 de junio. Fue al campo de los españoles en Cebú «un moro \{y\} llamado Damit", que dixo ser intérprete de la lengua malaya, el qual traýa el paño de manos blanco

${ }^{1}$ En Col., 1887: 91, se lee Sidamit, que parece dar mejor sentido. 
que el día antes llevó la india que enbió el governador a Çebú por señal de paz, y dixo cómo venía de parte de Tupas y prinçipales, como les dixo la india que embiase un intérprete, y que él era intérprete de la lengua malaya y d'estos naturales. Al qual habló el governador mediante Jherónimo Pacheco, intérprete de la misma lengua malaya» (Patron. 23: r. 22, f. 1r).

Algunas veces se necesitaron dos intérpretes, como ocurrió en el 25 de marzo: Urdaneta tradujo del español al malayo y Tuazán Malea del malayo al filipino. Hay una novedad en este viaje: el 2 de junio actuaron también como truchimanes indígenas de las islas, enarbolando previamente un pañuelo blanco como señal de paz. Otra cosa curiosa es que el intérprete fuese designado en Filipinas con una palabra náhuatl: naguatato, es decir, 'el hombre que sabe náhuatl'2. Así fue llamado Jerónimo Pacheco, como hemos visto.

La necesidad de los españoles y el avispado interés de algunos naturales hicieron que poco a poco aumentase el número de intérpretes. Estando todavía en Cebú, Legazpi logró que se bautizase un moro que era truchimán. Con esta ocasión se celebraron grandes fiestas:

El governador le mandó hazer muncha honra, con artillería, banqueta y toda la infantería en horden. Púsosele nonbre Mateo del Sauz [Mateo del Saz se llamaba el maestre de campo, sin duda su padrino, fallecido muy pronto, antes de 1567] y al hijo, Miguel, como el governador, el qual le añadió el don (Patron. 24: r. 2, f. 15r).

No era para menos: la conversión de un musulmán ladino a la fe cristiana constituía todo un acontecimiento digno de festejarse por todo lo alto.

No fue este Mateo el único en convertirse ni Pacheco el único español en saber lenguas. En 1570 Legazpi envió desde Panay a Martín de Goiti con el fin de explorar Luzón. Visto que los naturales de la isla no le abrían sus puertas, Goiti "por la lengua e intérprete que llebaba los requirió que le reçibiesen de paz, porque no iba a hacerles daño» (Patron. 24: r. 25, f. 1r) ${ }^{3}$. Lo mismo hizo Legazpi después: «Por la lengua que llebaba requirió a los naturales le rescibiesen de paz» (Patron. 24: r. 25, f. 1r). ¿Quién pudo ser este intérprete?

Otras fuentes, a lo que creo, permiten esclarecer su nombre. Legazpi, al aproximarse a Manila en 1571, vio que el reyezuelo Lacandola y Rajá Sulimán quemaban sus casas; entonces envió para disuadirlos de su acción al maestre de campo [que ya era Martín de Goyti], el cual «les habló en la ribera con un naguatato»

${ }^{2}$ Di ejemplos del término en mi libro Los chinos en Manila, (Gil, 2011: 784-785).

${ }^{3}$ Relación de Juan Pacheco Maldonado: «El dicho maestre de campo [Goiti] les dio a entender por lenguas» a los habitantes de «Manilla» (Patron. 46: r. 9). Así también en otra relación escrita el 20 de abril de 1572, Legazpi, en la entrevista con Rajá Suleimán, «le dixo con el intérpetre que se fuese a dormir a su casa y que otro día viniesen él y los otros dos raxás» (Patron. 46: r. 9). 
(Patron. 24: r. 23, f. 2r) $)^{4}$. Y un poco más adelante se habla de que un «naguatato spañol» (Patron. 24: r. 23, f. 2v) fue a parlamentar con los de Macabebe. Parece que se ha de tratar de Benito Díaz Bustos, a juzgar por la paz firmada por Legazpi con Lacandola y Sulimán «mediante Benito Díaz Bustos y Juan Mahomat, yndio christiano», el 18 de mayo de 1572 (Patron. 24: r. 24).

Después proliferaron los intérpretes, utilizados para todo, incluso para los menesteres más desagradables. Bajo el gobierno de Labezaris fueron a descubrir tierra el maestre de campo [Martín de Goiti] y el capitán Lorenzo Chacón. El 6 de junio de 1573 fray Francisco de Ortega se quejó de los malos modos que utilizaban los dos para recaudar tributos «sin guardar ley de Dios ni ynstruçión» del rey. Oigámosle:

Lo que hazen, en llegando a qualquier pueblo o provinçia, es ynbiar un nagualato o dos no con dádivas ni presentes, ni a predicarles ni dezirles cosas de Dios, sino a dezirles que traigan luego tributos y que sean amigos de los castillas (Patron. 24: r. 27 ).

He aquí un uso perverso de los lenguas que debió de ser usual en la cobranza de los tributos. Así lo confirma una escena paradigmática. Juan Marín atestiguó que en 1571, cuando subió río de Araut arriba al mando de Luis Pérez, los españoles

enviaron los lenguas a las simenteras a llamar los prinçipales; los quales les dixeron que se ausentasen, porqu'el año pasado avía benido el capitán Mangubu, qu'era Antonio Flores, y les avía pedido que le diesen tributo de oro, canpanas e tinajas, porqu'él no quería arroz, y así se lo dieron, que agora tenían arroz; y que quando tenían arroz, no querían sino oro; y agora que no tenían arroz, se lo pedían de tributo (Patron. 52: r. 6) .

En efecto, los habitantes de aquella región se morían de hambre, pues había arruinado la cosecha una plaga de langosta, plaga que se repitió varios años.

\section{INTÉRPRETES DE LENGUAS AUTÓCTONAS}

El intérprete es necesario en la guerra, pero no es menos necesario en la paz. Después del asentamiento de los españoles en Manila, se plantearon no pocos problemas de orden jurídico. En los litigios entre conquistadores y conquistados, vistos en primera instancia ante los alcaldes mayores, pasados en revista ante el gobernador y enviados en apelación a la Audiencia de México, fueron imprescindibles los servicios del truchimán.

\footnotetext{
${ }^{4}$ Carta del 11 de agosto de 1572.

${ }^{5}$ Probanza de Gabriel Rivera, hecha en Manila en julio de 1572.
} 
Por medio de los intérpretes llegaron también al rey de España las quejas de los naturales. Así ocurrió en 1582. El 15 de junio de ese año comparecieron ante el obispo fray Domingo de Salazar

çiertos indios que, mediante Françisco Morante y Andrés de Çervantes, yntérpretes de la lengua mora, dixeron llamarse don Luis Amanicalao y don Martín Porga y don Gabriel Tuan Boçar y don Juan Bantangad, christianos, y Salalila y Calao, Amarlenguaguay, ynfieles, y doña Françisca Saygan, prinçipales de los pueblos de Tondo, Çapa y Misilo con otros muchos número de prinçipales, y mediante los dichos yntérpretes dixeron que..., porque ellos pasan tantos agravios, molestias y vejaçiones, como a todos consta y es notorio, que le suplicavan muy umilmente [al obispo] sea servido de dar notiçia d'ello.

Las quejas formuladas contra los alcaldes mayores y sus oficiales fueron traducidas, pues, por dos españoles, que firmaron al pie del documento junto con el obispo y el escribano. Más noticias tenemos acerca de Francisco Morante, un soldado que hizo una información de sus servicios en Manila en mayo de 1590: había pasado a Filipinas en 1570, en la compañía del capitán Lorenzo Chacón; había participado en la conquista y pacificación de la Pampanga, Camarines, Guacilibón, Inagua, Laguno, Pangasinán, Ilocos, Cagayán; había luchado contra Limahón; en la campaña contra los indios de Tagurin había recibido un balazo en el muslo, por lo que le tuvieron que cortar la pierna, aunque la mutilación no le impidió ir a combatir al Maluco apoyándose en la muleta y andando con su pie de palo. Curiosamente, al enumerar sus hazañas, no se le ocurrió a Morante mentar su intervención como intérprete. Tampoco lo hicieron los testigos que presentó en la probanza ${ }^{6}$; podría haber parecido un desdoro citar sus habilidades lingüísticas entre sus relevantes méritos como hombre de armas.

La «lengua mora» a la que se alude tendría que haber sido el malayo; sin embargo, este Morante fue utilizado como intérprete de tagalo, según veremos más adelante, por lo que puede ser que el escribano de aquel documento sufriera una confusión o generalizara burdamente: como Cortés, cuando llamó 'mezquitas' a los cúes aztecas. Sea como fuere, prevalecieron, como es lógico, los intérpretes de tagalo, aunque muy pronto los religiosos se hicieron con la lengua y pudieron predicar a los indígenas sin necesidad de intermediarios en su idioma, del que hicieron y publicaron gramáticas.

En la instrucción que dio a Gómez Pérez das Mariñas el 9 de agosto de 1589, Felipe II le encargó muy encarecidamente que, para evitar «rencores y pasiones» en

${ }^{6}$ Fueron testigos Juan López de León, Andrés Sánchez, Antonio Garrido de Salcedo, Francisco Castillo, Miguel Núñez, Juan Ezquerra, Alonso Ligero, Antonio de Cañedo, Rodrigo Zarfate, Bartolomé de la Cruz. Quizá este Morante fuera hijo natural de Francisco Morante, uno de los primeros conquistadores de México, que después abrazó el hábito franciscano (México 204: n. 34). 
los pleitos que surgían entre españoles e indios y entre ellos mismos, el gobernador "en todo lo que fuere posible y buenamente se pudiere», concordase "las diferençias y pleitos que se ofresçieren sin llegar a tela de juicio, ni proçeder por los términos ordinarios, ni condenar en penas pecuniarias» (Filip. 339: libro I, f. 185r $\$ 30)^{7}$.

Das Mariñas obedeció la orden. La rapidez en evacuar los pleitos fue alabada en mayo de 1591 por los gobernadores de varios pueblos de la Pampanga (Pedro Lumano, de Bacolot; Miguel Manago, de Nuevo México; Nicolás Ramos, de Lubao; Miguel Oyón, de Guagua, y Alonso Libao, de Macabebe), que se mostraron muy conformes, quizá por la cuenta que les traía, con que no se admitiesen a trámite causas de más de siete años de antigüedad. A su vez, varios principales de Táal, Balangón, Molavi y Tanahuan atestiguaron, también en mayo de 1591 (Filip. 34: n. 91).

Un intérprete de tagalo aparece a causa de un escándalo morrocotudo en el que fue protagonista principal fray Cristóbal de Salvatierra, un hombre de armas tomar que, a la partida del obispo Salazar en 1591, quedó como provisor del obispado y gobernador de los naturales. Sucedió que el gobernador indígena de Tabuco, don Tomás Bulanbulán, vecino de Meitubu, presentó quejas contra un tagalo, el «fiscal»" de Benito Gutiérrez, el cura de Tabuco. El «fiscal» fue condenado a destierro y a una multa de seis pesos. Indignado, Gutiérrez suspendió al gobernador indio de su oficio por cuatro años, lo condenó a no tomar vino durante ocho años y le impuso una multa de 25 pesos, acusándolo de haber cometido diversos delitos contra la religión (culto a anitos y otras idolatrías). Enterado del caso, el gobernador de Filipinas, don Gómez, devolvió la vara a don Tomás. Fray Cristóbal, encolerizado, excomulgó al gobernador español. Se hizo una información para poner por escrito todos estos acontecimientos. El $1^{\circ}$ de diciembre de 1591 Salvatierra hizo parecer ante sí a Tomás Bulanbulán y le tomó interrogatorio; dice así el documento:

Del qual, mediante Thomás Taquil, reçiví juramento, so cargo del qual, prometiendo dezir verdad y siendo preguntado mediante Thomás Taquil, intérpete, si después acá que fue privado de la vara de governador y del ofiçio por el dicho provisor lo a vuelto a usar; y porque dijo que es verdad que lo a usado etc. (Filip. 6: r. 7, n. 91).

Lo más interesante de este caso es que el intérprete fue llamado por los españoles para conocer la sustancia de un conflicto que, en su origen, se había producido entre miembros de la propia comunidad indígena, aunque después el desarrollo de los acontecimientos hubiese acabado por involucrar en él a los más altos personajes

\footnotetext{
${ }^{7}$ Se vuelve a insistir en ello en Filip. 339: libro I f. 194r $\$ 52$.

${ }^{8}$ Los fiscales son «los ministros de que usan [los eclesiásticos] para lo que quieren hazer, que llaman fiscales, y son crueles executores de las voluntades de los relijiosos»: así aclaró el término Rodrigo Díaz Guiral, en carta al rey del 30 de junio de 1606 (Filip. 19: r. 7, n. 100).
} 
de todas las islas. Y en este caso la presencia del truchimán dio un cierto carácter oficial al interrogatorio, pues el propio fray Cristóbal era «lengua» de los indios ${ }^{10}$ : no necesitaba, pues, de intermediario para hablar con Bulanbulán, pero prefirió actuar como juez y no poner en tela de juicio su imparcialidad.

Pero estos intérpretes parecen haber sido intérpretes ocasionales. El intérprete es una persona que, una vez que ha prestado sus servicios, apenas tiene utilidad... hasta la siguiente ocasión. De ahí que el indígena ladino no aparezca normalmente en la documentación como lengua, sino como criado. Es el caso, por ejemplo, del pampango Martín, que en 1586 marchó a España como sirviente del jesuita Alonso Sánchez (Pastells, 1925: II, CCCXXXVII). Ante los ojos de una asombrada Europa, los religiosos necesitaban mostrar a los aborígenes de tierras lejanas como prueba de sus éxitos misioneros en lugares de un mítico exotismo. Otro tanto habían hecho los franciscanos en el siglo XIII: la naturaleza humana no se puede resistir a estas pequeñas vanidades.

\section{INTÉRPRETES DE CHINO}

De los intérpretes de chino hay abundantes noticias. Baste recordar, en los primeros tiempos, el nombre de Sinsay, que fue truchimán con el corsario Limahón y con el capitán imperial Homoncón y que prestó grandes servicios en la primera embajada de los españoles al Fujian (1574-1576) (Gil, 2011: 28). En el segundo viaje las cosas no rodaron tan bien: los chinos dejaron a los frailes en la costa de Ilocos «y a un lengua que los religiosos llevaban natural de la China le maltrataron a azotes, que está a punto de morir» ${ }^{11}$. El mismo sino corrió un chino cristiano de Macao que en 1587 acompañó a Cantón al franciscano Martín Ignacio de Loyola: en presencia del fraile, lo «azotaron fuertemente» (Apol., 1598: cap. VI; Pastells, 1925: II, CCXVII). El oficio de truchimán, a veces, comportaba no pocos riesgos.

Fueron los mismos chinos ladinos quienes se encargaron de la primera evangelización de los sangleyes. Así consta por una carta del fiscal Ayala, en la que cuenta que los chinos, «diçiendoles por intérpretes cosas de nuestra fee, gustan de oírlas, y dizen serán christianos de buena gana como no les corten el cabello»; y sigue contando

${ }^{9}$ La desmesurada actuación del fraile le valió una severa reprimenda por parte de Felipe II el 13 de junio de 1594: «Me a desplacido, pues no deviérades escandaliçar el pueblo con semexante demasía; y porque no se a de dar lugar a ellas, se os advierte que tengáys gran respecto al governador y que no os entremetáys a conoçer contra legos fuera de los casos que de derecho aya lugar y, en ellos, guardando el horden de derecho y el respecto qu'es justo tenerle» (Filip. 339: libro 2, f. 67v-68r).

${ }^{10}$ Así lo especificó el obispo Salazar al justificar que lo hubiese nombrado su lugarteniente de protector: «confiando de la rectitud, letras y buena vida de fray Christóval de Salvatierra..., y que es lengua de los dichos yndios y que a muchos años que los tiene a su cargo» (Filip. 6: r. 7, n. 91).

${ }^{11}$ Carta del cabildo de Manila del 2 de junio de 1576 (Pastells, 1925: XLVII). 
que a un chino principal «todos los días se ocupa en enseñarle cosas de nuestra santa fee un intérprete dos oras» (Filip. 18A: r. 3, n.12 $\$ 30,31)^{12}$. A pesar de la oposición de los agustinos, el presidente de la Audiencia, Santiago de Vera, favoreció desde un primer momento la misión de los dominicos:

Les encargué la doctrina de ellos y les di intérpretes, para que les enseñasen la lengua, y les mandé hazer iglesia y casa en la alcaizería, que llaman el Parián, y en la punta de Tondo, donde tienen sus tratos y bibienda. Y se an dado tan buena maña dos relijiosos, que el uno de ellos entiende y abla ya bien la lengua, y el otro la sabrá con brevedad (Filip. 18A: r. 7, n. 46) ${ }^{13}$.

Pero estos intérpretes de chino, como los de tagalo, son personajes de utilización efímera. Una vez cumplido su cometido, hacen mutis por el foro. Es lo que ocurre en otros casos. Cuando don Pedro de Acuña firmó un tratado de paz con Cachil Sultán Zaide, rey de Terrenate, el 10 de abril de 1606, hizo de intérprete «Pablo de Lima, portugués, natural d'estas islas [el Maluco]» (Patron. 47: r. 5); de este Pablo de Lima no se volvió a hablar en la documentación filipina.

\section{LA AUDIENCIA. CREACIÓN DE UN SERVICIO DE INTÉRPRETES OFICIALES}

Con la creación de la Audiencia de Filipinas (8 de junio de 1584) cambió radicalmente la situación, ya que con ella se institucionalizó la figura del intérprete. En las instrucciones dadas a la Audiencia en 1583 se dictaron normas específicas -nada menos que doce capítulos- sobre los deberes y obligaciones de los lenguas (Gil, 2011: 245-247). A ellos se refiere una carta del fiscal Ayala, escrita el 15 de julio de 1589, en la que se enumeran los funcionarios que trabajaban en la Audiencia: además de los magistrados nombrados por el rey, había «un secretario y un relator y tres procuradores e intérpretes y otros offiçiales» (Filip. 18A: r. 7, n. 49).

Desconozco los nombres de los intérpretes nombrados por la primera Audiencia, que cesó con la llegada del gobernador Gómez Pérez das Mariñas. Es probable que fueran los mismos hombres que desempeñaron ese cargo pocos años después. En efecto, desde el 8 de junio de 1598, el día en que se fundó la segunda Audiencia, hasta el primero de septiembre de 1618 los oidores nombraron a los siguientes intérpretes de tagalo:

-15 de junio de 1598: Juan García de Moraga. Pasó en 14 de diciembre de 1599 a ser intérprete del protector.

-13 de junio de 1598: Francisco Morante.

-15 de julio de 1598: Diego de Mercado.

\footnotetext{
${ }^{12}$ Carta del 20 de junio de 1585.

${ }^{13}$ Carta del 13 de julio de 1589.
} 
-Francisco Morante, intérprete de la Audiencia, cobró $20{ }^{\mathrm{ps}}$ por un año, que empezó a correr desde $1^{\circ}$ de junio de 1603 (Contad. 1206, f. 577v, correspondiente al año 1605; el salario se contó en "Gastos de justicia»).

-24 de enero de 1607: Antonio Palomeque.

-10 de octubre de 1609: Andrés de Guevara.

-23 de octubre de 1615: Pedro Jerónimo. No se especifica lengua (Filip. 7: r. 5, n. 60).

Como se ve, la Audiencia procuró recompensar a los españoles que sabían la lengua indígena con el nombramiento de intérprete, con preferencia a los naturales ladinos. Era una manera de aliviar su maltrecha economía mediante un pequeño sueldo. Por tanto, es probable, como he dicho antes, que este cargo lo desempeñasen desde el principio españoles como Andrés de Cervantes y Francisco Morante, que ejercieron de intérpretes antes de la creación de la Audiencia.

La misma pauta se había seguido tanto en la Nueva España como en el Perú. Baste dar aquí unos cuantos ejemplos. Álvaro de Zamora, uno de los conquistadores, fue intérprete durante muchos años de la Audiencia de México (México 205: n. 33 ${ }^{14}$. En 1588 Francisco de Leiva fue nombrado intérprete de la misma Audiencia, por suspensión de Diego de León (México 173: n. 61). En 1600, el licenciado Francisco García de Medrano hizo una información a tal fin en Lima para probar que era «ábil y suffiziente en la lengua general de los naturales de este reyno» (Lima 213: n. 6) ${ }^{15}$. A su vez, Juan Bautista Pinto era «uno de los lenguas generales que ay en este reyno [Chile]» en 1614 (Patron. 229: r. 48).

El sueldo, aunque no muy elevado, contribuyó a hacer apetecible el cargo: Francisco de Leiva tenía un salario de 200 pesos en México; a mediados del siglo XVII, el intérprete de la lengua de los indios de la Audiencia de Lima ganaba 400 pesos ensayados (BN, ms. 3046: ff. 36v-37r.). No era mucho, pero significaba una ayuda no despreciable.

Los chinos ayudaron a los españoles en sus viajes a China. Cuando fue despachado a Cantón el padre Alonso Sánchez, le escribió una carta de presentación al tután «uno de los capitanes de los navíos chinos que de la ciudad de Chincheo vienen a contratar a la de Manila», aunque ningún «lengua» quiso acompañarlo por miedo a dicho magistrado, que había impuesto la pena de muerte a todo aquel que guiase a algún extranjero a su reino (Pastells, 1900: 266) ${ }^{16}$. De chino hubo en Manila varios intérpretes oficiales:

-El intérprete de la Audiencia. Tenían un sueldo de 80 pesos (Gil, 2011: 678-681). -El intérprete que acompañaba a los oficiales reales en la inspección de las naves llegadas de China. A mediados del siglo XVII ganaban 100 pesos al año (Gil, 2011: $41,47,572$ y 573$)$.

-El intérprete del parián (Gil, 2011: 656, 674 y 676).

\footnotetext{
${ }^{14}$ Información hecha en México en 1559.

${ }^{15}$ Primera pregunta en la probanza realizada en Lima.

${ }^{16}$ Se trata de una Relación escrita por el padre Sánchez.
} 
Solo en una ocasión se menciona, en la lista anteriormente citada, a un intérprete de chino y de japonés: lo fue Andrés Gonzalo, nombrado por la Audiencia el 20 de diciembre de 1618 .

La condición oficial del intérprete dignificó su figura y le otorgó, además, otra ventaja indiscutible. Conocer los deseos del pleiteante y, al mismo tiempo, pertenecer a la administración de justicia le permitía aconsejar a las partes, actuar de intermediario entre el litigante y el juez y, en ocasiones, reclamar favores o exigir cohechos. Era fácil caer en la tentación de enriquecerse prevaricando. Y muchos sucumbieron a ella. Felipe II promulgó ya en 1563 una serie de medidas para atajar el mal, prohibiendo a los intérpretes llevar interés alguno, recibir dádivas, oír en sus casas las causas de los indios o actuar como sus abogados (Recop., 1681: I 273-274, libro II título 29, leyes 2, 3, 6 y $7^{17}$. Las mismas recomendaciones se hicieron en la instrucción dada a la Audiencia en 1593 (Gil, 2011: 245-246). Fue inútil. La débil naturaleza humana volvió a incurrir en los mismos vicios y excesos, a los que intentaron poner coto el virrey de México, don Luis de Velasco, el 20 de febrero de $1592^{18}$, y Felipe IV,

${ }^{17}$ El título 29 se encabeza «De los intérpretes».

${ }^{18}$ Ordenó el virrey que «los intérpetes que al presente son y por tiempo fueren d'esta real Audiencia, ni alguno d'ellos, de aquí adelante por ninguna vía traten ni comuniquen con los dichos indios d'esta çiudad y pueblos d'esta Nueva España los dichos pleitos, caussas y negocios en sus cassas ni en otras partes, ni de ellos reçivan petiçiones ni pinturas para traerlos ante su señoría ni a la dicha real Audiençia, ni les hagan algunas de las dichas petiçiones y pinturas, ni soliçiten con otras personas que se las escriban y hordenen, a los quales dexen ir derechamente a la cassa del dicho liçençiado Baldés [el abogado oficial de los indios] para que, aviendo dado noticia del negoçio que traen o pretenden pedir, lo pidan y hagan sus peticiones conforme a lo que le está otorgado y encargado en el auto de su nombramiento; y para ser informado de los dichos indios de los negoçios a que vinieren y lo que pretenden pedir, asista hordinariamente en su cassa uno de los dichos intérpetes, cada mes por su turno, començando del primero, el qual solamente interpete lo que los dichos indios dixeren y trataren; y después de averles despachado el dicho letrado las /1v/ petiçiones y relaçiones que les hiziere, las reciva el dicho Pero Díaz de Agüero, su procurador, el qual, y no el intérpete, las trayga ante su señoría o a esta real Audiençia, donde se huvieren de presentar, para que se provean en la forma que conveniere y está ordenado; y la provissión, decreto y despacho d'ella la reçiva el dicho procurador, y él de su mano pague a los secretarios sus derechos en los cassos y cossas que los devieren llevar, y entregue a los dichos indios los despachos, sin que en ello ni en parte d'ello el dicho intérprete que huviere de asistir en cassa del dicho letrado, ni ninguno de los demás, se entremeta a soliçitar los dichos despachos; y que por razón de la dicha interpretación ni assistir en la dicha caussa no lleve de los dichos indios ni de algunos d'ellos ni de sus comunidades derechos algunos en poca ni en mucha cantidad, ni d'ellos los resçivan, aunque se los quieran dar de su voluntad; y que los demás intérp<r>etes asistan en estas cassas reales y salas de los oydores y alcaldes para que, ofreciéndose negoçio en que sea necessario, usen sus ofiçios anssí en reçivir informaçiones y provanças y tomar confessiones y declaraçiones y hazer otros autos, los puedan usar, sin que por ninguna vía los comuniquen y traten antes de hazerse los dichos autos, informaçiones y provanzas, por las quales, tocando a indios particulares, no los an de llevar derechos algunos, salvo a las comunidades, consejos y universidades de los dichos pueblos y a los caciques y prinçipales, y a estos solamente la mitad de lo que pueden y deven llevar, comforme al aranzel d'esta real Audiençia; y que por ninguna vía reçivan ni lleven de los dichos indios y sus comunidades ningunas dádivas, serviçios ni cossas de comer ni beber para sí, ni dineros algunos para pagar los derechos a los secretarios y relatores 
el 13 de junio de 1623 (Recop., 1681: II 218a, libro VI título 6, ley 4). Hubo muchas quejas contra los intérpretes, como veremos. En 1647 Bernabé de Vera fue suspendido de su oficio «por dezir avía interpretado siniestramente». No hubo de ser el único.

\section{EL PROTECTOR DEL INDIO}

Capital también para la formación de una burocracia administrativa y, en definitiva, para la creación del oficio de intérprete fue la figura del protector del indio, un magistrado creado para mirar por el buen tratamiento y amparo de los naturales y defenderlos en sus pleitos, causas civiles y criminales y demás negocios. Felipe II ordenó con firmeza reimplantar la protectoría, denigrada y hasta suprimida durante un tiempo (Recop., 1681: II 217a, libro VI título 6, ley 1a) ${ }^{19}$.

Por ley, la protectoría correspondía al fiscal de la Audiencia (Recop., 1681: II 237a, libro II título 18, ley 24$)^{20}$. Como los primeros años de la gobernación de Filipinas transcurrieron sin Audiencia, Francisco Bañón, uno de los primeros conquistadores, pidió al rey que le hiciera "protector general de todos los naturales de la ysla de Luçón». Su petición encontró una respuesta negativa por parte del Consejo de Indias el 9 de agosto de $1577^{21}$.

En 1582 el obispo de Manila, fray Domingo de Salazar, se intituló «padre de pobres miserables y protetor y amparador d'ellos», en este caso, defendiendo a un chino contra una sentencia del tesorero don Antonio Jofré Carrillo (Filip. 85: n. 35). Es probable, en consecuencia, que, si no de derecho, desempeñase de hecho ese cargo.

Cuando se creó la primera Audiencia en Filipinas (1584), Felipe II encomendó a su presidente, el licenciado Santiago de Vera, que se informase sobre la persona más idónea para tomar a su cargo la protectoría. El 20 de junio de 1585, a poco de llegar, Vera excluyó de ese oficio al fiscal, la persona designada en principio por la ley, por las incompatibilidades que entrañaba el ejercicio de su cargo: «El fiscal no puede defender todas las caussas de los yndios: por la ocupaçión de su offiçio se be cada día que se enquentra con el de protector». En su lugar, propuso una terna: Tomás Pérez, Luis de Vivanco y Benito de Mendiola, «de quien se tiene buena opinión y son hombres

y relatores, ni les soliçiten sus caussas, so pena que, por qualquiera cossa que exçediere de lo contenido en este auto, incurran en pena de privación de sus ofiçios y en destierro d'esta çiudad con diez leguas a la redonda por tiempo de quatro años preçissos, demás de que pagarán y satisfarán todo lo que llevaren de los dichos indios contra el tenor y forma de lo susodicho, con el quarto tanto para la cámara de Su Magestad» (México 22: n. 72).

${ }^{19}$ Cédula dada el 10 de enero de 1589, encabezándose el título 6 «Delos protectores de los indios».

${ }^{20}$ Se trata del título «De los fiscales de las Audiencias».

${ }^{21}$ Así consta de su información de servicios, hecha en Manila en 1574; la contestación del Consejo, por ser de fecha posterior, debe de haber sido intercalada más tarde (Patron. 52: 8, f. 1v-2r). 


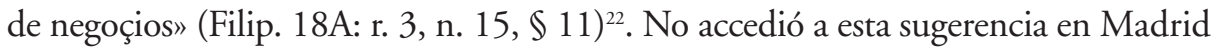
el Consejo de Indias, que siguió encomendando los asuntos de los naturales al fiscal ${ }^{23}$. Pero Vera, sin esperar contestación, nombró protector a Mendiola, nombramiento que recibió el apoyo de los agustinos. El elegido era:

casado, hombre de bien y mui hábil y suficiente para él; y lo a hecho con buen zelo y cuidado, aunque por ser pobre y el salario que se le dio, poco -que es çien pesos-, esle forçado a acudir a otros negoçios, y así no puede dexar de hazer faltas en los de los indios»; por tanto, lo mejor era que se le confirmara en el cargo, eso sí, con un buen sueldo (Filip. 84: n. 18) ${ }^{24}$.

Mendiola fue el primero, a lo que sé, que desempeñó al mismo tiempo el oficio de protector de los indígenas y de los chinos (Gil, 2011: 215-216). Fue, sin embargo, una imprudencia la unión de los dos cargos. En efecto, la protectoría de los chinos, que podía reportar pingües beneficios, menoscaba de hecho la defensa de los naturales. No solo restaba tiempo a su titular para actuar en defensa de la mayoría de los habitantes de las islas, sino que, en caso de conflicto entre un tagalo y un sangley, el primero llevaba todas las de perder, al no estar apoyado por una comunidad tan pudiente y poderosa como la china.

Después ocupó ese puesto el fiscal Ayala. Su actuación no fue aprobada por fray Domingo de Salazar, el obispo de Filipinas. En efecto, en un memorial entregado a Alonso Sánchez en 1586, el obispo de Filipinas no solo pidió a Felipe II que el fiscal dejase de ser el protector de los indios, sino que solicitó ese puesto para sí, con facultad de tener un ayudante con salario y añadiendo que, en caso de que no lo fuera el prelado, el protector fuese nombrado de común acuerdo por el gobernador y el obispo (Pastells, 1925: II, CCCXLI [Memorial \$\$ 36-37]).

Tampoco el jesuita Alonso Sánchez sintió simpatía ni por el protector ni por los intérpretes. En las acertadas recomendaciones que desde Roma dio al gobernador Gómez Pérez das Mariñas antes de la partida de este a Filipinas figuran dos que nos interesan particularmente: le avisó de que los agravios infligidos a los indios provenían «de los protectores españoles, que debaxo d'este nombre los roban«y «de los nauatatos o intérpretes, que también los desuellan» (Pastells, 1925: III, XXXIX). Es la primera vez que salen juntos a colación el protector y los intérpretes, prueba de que los segundos solían trabajar a las órdenes del primero.

${ }^{22}$ He aquí cómo fue presentado ante el rey: «Benito de Mendiola. Passó a estas islas el año de setenta y quatro. A usado ofiçio de procurador y a sido protetor de los naturales. Está cassado. Tiene algún caudal. Será de hedad de quarenta y cinco años» (Memoria de los encomederos de Filipinas en 1599: Patron. 25, r. 55).

${ }^{23}$ Se escribió al margen del resumen de la carta: «Que en esto se guarden las cédulas qu’están dadas, y el fiscal los defienda en lo que pudiere».

${ }^{24}$ Carta al rey del 20 de julio de 1581 , una fecha equivocada. 
El mismo padre Sánchez entregó a Felipe II un memorial de las cosas que pedían los españoles que habitaban en Filipinas. Entre sus solicitudes estaba que, para evitar los daños que inferían los protectores a los naturales, se encargase de la defensa de estos y de los chinos «un hombre christiano y de autoridad", pero que no fuera el fiscal, «porque de necesidad se le ofrecen en su officio más causas contra los indios que en su deffensa, las quales no puede dexar de seguir; por do parece que estos dos officios no se compadecen en una persona»; tampoco, lógicamente, habría de ser encomendero (Patron. 24: r. 66, f. 50v, cap. V apart. 50) ${ }^{25}$.

En 1589 Felipe II accedió a las súplicas del obispo Salazar y lo nombró protector de los indios. Así se lo comunicó tanto a Gómez Pérez das Mariñas como al propio obispo (Filip. 339: libro I, f. 186v, $\$ 33)^{26}$. Mas el gobernador, llegado a Manila en 1590, hizo ver que el prelado no podía asistir personalmente a los actos judiciales que exigían la presencia corporal del protector. En efecto, fray Domingo, que había decidido acudir a presencia del rey para exponerle en persona la situación de Filipinas, había dejado como gobernadores del obispado al cabildo y a su compañero de orden fray Cristóbal de Salvatierra (20 de junio de 1591) (Filip. 6: r. 7, n. 83) ${ }^{27}$; mal podía ejercer la protectoría en ausencia, por mucho que en el ínterin fray Cristóbal se intitulase pomposamente «governador de los naturales de las islas por fray Domingo de Salazar» ${ }^{28}$.

En vista de este reparo razonable, el monarca, en un capítulo de una larga carta despachada a don Gómez el 17 de enero de 1593, le dio facultad para nombrar a un nuevo protector con un salario conveniente, que se habría de obtener haciendo una prorrata sobre las tasas de los indios (Filip. 339: libro II, f. 31r. ${ }^{29}$. En uso de ese poder, el 12 de abril de 1595 el gobernador interino, Luis Pérez das Mariñas, otorgó ese puesto a Blas Escoto de Tovar, que había sido relator de la Audiencia de México en la sala del crimen y había pasado a Filipinas, en 1593, como juez auditor de la armada de socorro que había enviado el virrey Velasco desde la Nueva España ante la amenaza de invasión por parte del shogun Hideyoshi ${ }^{30}$. En este nombramiento se perfila

${ }^{25}$ Es curioso que, según los usos de aquella época, se previera incluso dónde tenía que sentarse: tenía que tener voz y voto en el cabildo "preferido a los regidores y alguacil mayor, que se siente con los abogados y no con los procuradores».

${ }^{26}$ «Él [el obispo] olgará de admitir ese cuidado, por lo que toca al serviçio de Nuestro Señor y descargo de su conçiençia».

${ }^{27}$ Copia del nombramiento de gobernadores.

${ }^{28}$ Así se intituló el 10 de noviembre de 1591 (copia de la escritura en Filip. 6: r. 7, n. 91). En efecto, el mismo 20 de junio de 1591 el obispo lo nombró «nuestro lugarteniente en todos los negoçios y casos matrimoniales, çeviles y criminales que entre los dichos yndios se ofresçieren de tratar y trataren, así en esta çiudad como en todo este obispado, los quales pueda sentençiar y determinar conforme a derecho» (copia de la escritura, hecha el 23 de diciembre de 1591).

${ }^{29}$ Este capítulo está reproducido en Recop., 1681: II 218b, libro VI título 6, ley 8.

${ }^{30}$ Blas Escoto, hijo de Juan Clemente, relator de la Audiencia de México durante muchos años, y nieto del capitán Ángel de Barboa, alcaide de Gibraltar, había pasado a España para presentar allí sus papeles y buscar cartas de recomendaciones para el virrey del Perú. Pidió licencia para volver a México en 1587 (Indif. 2063: n. 101), licencia que le concedió el rey el 31 de agosto de 1589 (Indif.: 2098, n. 65). 
más claramente el núcleo administrativo de apoyo a la función del protector. Estos fueron los términos en que se expresó don Luis:

Y porque, para mejor acudir a lo que conviene al bien de los dichos naturales, es neçesario que en cada provincia d'estas islas, especialmente de las que están muy apartadas d'ellas, como es en Çebú, Otón, Camarines, Ylocos y Cagaián, tenga personas que en su nombre y con su poder acuda $<\mathrm{n}>\mathrm{al}$ anparo de los naturales d'ellas que tenga cuidado de darle aviso de las cossas que convienen remediar, le doy poder y facultad, qual de derecho se requiere, para que pueda nombrar y sustituir las dichas personas, siendo de toda confianza, retitud y christiandad, y en esta ciudad asimismo pueda tener otro que sea visiprotetetor que acuda a la soliçitud y buen breve despacho de los negoçios de los naturales; y que tenga intérpete nombrado para el despacho de los dichos naturales, sin que por ello el dicho licenciado ni los demás puedan llevar ni lleven ningunos derechos... Le señalo de salario mill y ochocientos pesos de oro común en cada un año de los que sirviere, que comience a correr y contar desde oy, día de la fecha d'esta; el qual dicho salario le señalo y mando le sea librado y pagado sobre los tributos que los naturales de esta ysla an de dar y pagar en cada un año a sus encomenderos, rata por cantidad entre los que están en la real corona y para particulares, según y como Su Magestad lo manda (Filip. 59: n. 35, foto 13).

Pronto se echó de ver que una corrección de los desmanes cometidos por los españoles solo sería de verdad posible y efectiva si se efectuaba previamente una inspección general del archipiélago. El 15 de octubre de 1596 el gobernador Francisco Tello nombró a Blas Escoto visitador de las islas, con un sueldo de cuatro pesos diarios. En esta ocasión también salieron a relucir los oficiales que lo habrían de acompañar a fin de ayudarlo en su tarea: el escribano Fernando Menéndez de Valdés y el alguacil Diego de Herrera, los dos con el mismo salario (un peso diario más los derechos de escritura). Como no podía ser menos, también se le asignó un intérprete, en este caso con una salvedad.

Y porque podría ser aver diversidad de lenguas en la dicha visita de vuestra juridiçión y comissión, y un intérpete no las sabría todas, os doy comición y facultad para que podáis nombrar en la visita el intérpete que os pareciere convenir según la ocaçión en que os halláredes, con que el salario que le señalardes no exceda de quatro reales cada día (Filip. 59: n. 35, foto 13).

Aquí, en la cuantía de los emolumentos, se ve claramente la estima que tenía entonces un intérprete: no podía ganar más de la mitad de la paga del escribano y del alguacil, que percibían otras cantidades extra por el cobro de sus derechos. Claro está que los otros dos cargos estaban desempeñados por españoles, mientras que el intérprete tendría que ser un filipino; para la mentalidad clasista de la época, el oficio de truchimán no estaba mal pagado ${ }^{31}$.

${ }^{31}$ De Blas Escoto se conserva una petición hecha en junio de 1595 a Luis Pérez das Mariñas, solicitando que no pagasen derechos las cuatro toneladas de ropa que cargaba cada año en el galeón el Hospital de los pobres, administrado por los franciscanos (Filip. 79: n. 30). 
La visita, que comenzó en Cebú en enero de 1597, se vio interrumpida por un suceso inesperado: el anuncio de que se había refundado en 1596 la Audiencia de Manila con el nombramiento como oidores de Cristóbal Téllez de Almazán y Álvaro Rodríguez Zambrano. Ante esta nueva se suspendió la inspección, que había llegado a la provincia de Pintados, y el 29 de octubre de 1597 Tello volvió a nombrar protector a Blas Escoto, esta vez con un sueldo de 900 pesos.

Un nuevo incidente truncó la carrera de Escoto. El 23 de junio de 1587 el rey había decidido que correspondiese al fiscal de la Audiencia la protectoría de los indios. Por tanto, con la llegada del nuevo fiscal, el licenciado Jerónimo de Salazar y Salcedo, Escoto se quedó en paro. En una información de sus servicios, hecha en Manila en junio de 1598, todos los testigos estuvieron de acuerdo en que era una persona de ciencia, conciencia y experiencia en quien cabía cualquier $\mathrm{cargo}^{32}$; desgraciadamente para él, no obtuvo ninguno. Pero volvamos a Salazar.

En 1597, Salazar partió de Sevilla en compañía de su mujer, doña Ana de Saavedra, y de una hija soltera, doña Juana de Salazar, tras dar fianzas en cantidad de 200.000 mrs. de que residiría ocho años en las islas (Contrat. 5252: n.2., r. 67) ${ }^{33}$. A Manila llegó dos años más tarde, en 1598. Recién estrenado en su puesto (había llegado con los oidores el 23 de mayo), Salazar envió una carta a Felipe II el 6 de julio de 1598 en la que, entre otras cosas, le dio jugosas noticias acerca de las medidas que había tomado para reforzar su actuación como protector:

Por una real cédula me mandó Vuestra Magestad que fuese protector de los indios naturales de estas yslas. Y por ser el trabajo de ello grandíssimo, y muchos sus pleitos, y más los agravios que se les hacen, y haver menester otro solicitador para ello y un intérprete, me dio licencia el Audiencia para poderlos nombrar, el solicitador con doscientos pesos de salario, y el intérprete, con ochenta, pagados en la forma en que se pagaban al licenciado Blas Escoto de Tobar, protector de los naturales de estas islas, mil y doscientos pesos que cada año tenía por ello de salario a costa de los dueños de las encomiendas de los indios; lo qual ha cesado con el ser yo el protector, y solo pagan los dueños de las encomiendas estos doscientos y ochenta pesos de mi solicitador y intérprete en esta protectión (Filip. 18B: r. 8, n. 103) ${ }^{34}$.

${ }^{32}$ También abogó por él el jesuita Raimundo de Prado en carta del 30 de junio de 1598: «Ha sido abogado en esta ciudad con buena opinión» (Filip. 79: n. 35). De él se dijo un año después: «Blas Escoto de Tovar. Passó a estas islas el año de noventa y tres y ase ocupado en abogar y en la protetoría de los naturales d'estas islas hasta que llegó la Audiencia. Casose, y tiene caudal. Es de edad de treinta y seis años» (Memoria de los encomenderos de Filipinas en 1599: Patron. 25: r. 55).

${ }^{33}$ La carta fue dirigida a los oficiales de la Contratación, fechada el 13 de noviembre de 1596 (Filip. 339: libro II, f. 114r.)

${ }^{34}$ El Consejo de Indias, al que esta medida cogió de sorpresa, anotó al margen de la carta: "Que al nuevo governador se le ordene que trate esto con la Audiencia y, siendo necessarios estos ministros, lo assiente assí y les haga pagar los salarios, procurando sean personas suficientes y de confiança para estos ministerios». 
Ya tenemos asentado el sueldo que se iba a dar al intérprete en el futuro: 80 pesos; si bien estos gastos quedaban compensados con la supresión de un cargo.

No tardaron en surgir adversidades y contratiempos. A los pocos meses de su llegada, el 12 de septiembre de 1598 murió doña Ana de Saavedra, su mujer. Al drama familiar se unió el desánimo producido por la sensación de impotencia en su desempeño profesional. En efecto, poco podía hacer el fiscal en su ministerio de protector de los indios. Así lo confesó sin ambages Salazar el 22 de julio de 1599. Bien hubiese querido él cumplir con sus obligaciones con los naturales, pero la propia naturaleza de los litigios se lo impedía, pues muy a menudo se planteaba un conflicto de intereses:

Aunque desseo acudir con muchas veras, no puedo todas vezes, porque las más causas que los indios tienen son criminales y contra la real Hazienda, a las quales, aviendo yo de acudir como fiscal, no puedo de ninguna suerte defender los indios en ellas.

Por ello propuso Salazar, muy razonablemente, que el oficio de protector recayese en otra persona, y que esta persona, a su vez, nombrase tenientes en todas las islas para defender debidamente a los indios (Filip. 18B: r. 9, n.130).

Deprimido por la viudedad y agobiado por el clima tropical de Manila, Salazar solicitó el 24 de julio de 1599 la plaza de oidor, vacante por el fallecimiento del licenciado Álvaro Rodríguez Zambrano (Filip., 18B: r. 9, n. 131). Al menos, el ascenso profesional podría compensar sus achaques y cuitas. Gran chasco. En 1603, acompañando al gobernador Acuña, llegaron nuevos oidores: los licenciados Andrés de Alcaraz y Manuel de Madrid y Luna ${ }^{35}$. El 5 de julio de 1603 Salazar volvió a repetir la triste cantilena, pidiendo al rey que, como «lo más de cada un año» estaba «indispuesto con las grandes calores d'esta ciudad", le concediese su traslado a México o a Lima, capitales más conformes con su salud (Filip. 19: r. 4, n. 68) ${ }^{36}$. No pudo ser. El 30 de junio de 1605 la Audiencia dio cuenta de que su fiscal había fallecido pocos días antes, el 13 de abril, «después de una larga y prolija enfermedad»; en su puesto fue nombrado interinamente el licenciado Rodrigo Díaz Guiral (Filip. 19: r. 6 , n. 91$)^{37}$.

Juan de Alvarado Bracamonte, fiscal de la Audiencia, consiguió antes de emprender el viaje que el rey premiase sus servicios el primero de mayo de 1607, añadiendo a la protectoría de los indios la de los chinos (Filip. 21: r. 2, n. 3). En

${ }^{35}$ Dio cuenta al rey de su llegada el 4 de julio de 1603 (Filip. 19: r. 4, n. 62).

${ }^{36} \mathrm{El} 23$ de junio de 1604 los oidores nombraron fiscal interino al licenciado Luis Ortiz de Padilla, «por enfermedad e in $\{$ te\}pedimiento del licenciado Salazar y Salzedo, propietario» (Filip. 7: r. 5 , n. 60).

${ }^{37}$ El nuevo fiscal, natural de Chillón, había pasado a Filipinas como criado del oidor Téllez de Almazán (Contrat. 5251B: n. 2, r. 3). «Acude al serviçio de Vuestra Magestad con mucho cuydado y diligençia», escribieron los oidores en carta al rey del 10 de julio de 1606 (Filip. 19: r. 7, n. 107). 
ambos oficios procedió «con mucha y conoçida rectitud, prudençia y cuydado», a juicio de los agustinos y franciscanos de Manila ${ }^{38}$.

Esta decisión regia, sin embargo, desagradó profundamente a la Orden de santo Domingo. Su procurador, fray Melchor Manzano, pidió que se quitase a la fiscalía la protectoría de sangleyes; decía el predicador actuar en nombre de los propios chinos, esgrimiendo las mismas razones que había usado antes Santiago de Vera para denegar ese cargo a Ayala: los sangleyes «no querían protector, o, en caso que se les diese, que no fuese el fiscal, por ser officios incompatibles; y que, de tenerlo el dicho fiscal, avían experimentado por espacio de muchos años serles antes dañoso que provechoso». Su solicitud fue aceptada el 23 de noviembre de 1627 por el Consejo de Indias, que dejó el nombramiento de protector en manos del gobernador. Don Fernando de Silva devolvió la protectoría de los sangleyes, junto con la de los naturales, al fiscal Marcos Zapata.

El fiscal Juan de Saavedra Valderrama fue nombrado protector de los indios el 19 de febrero de 1619.

Volvió a reclamar la protectoría de los sangleyes el fiscal Juan de Quesada Hurtado de Mendoza, alegando que él, como persona de mayor autoridad, podría defender mejor los intereses de los sangleyes. "No a lugar lo que pide», anotó el doctor Velázquez el 22 de marzo de 1628. El acuerdo que el Consejo de Indias tomó en Madrid fue que el gobernador y la Audiencia nombrasen seis candidatos apropiados, para que entre ellos el Consejo eligiera por un tiempo indefinido al protector, «el qual no aya de tener tratos ni granjerías con los sangleyes» (Filip. 21: r. 2, n. 3). El 26 de marzo se le concedió a Quesada, sin embargo, la protectoría de los indios (Filip. 21: r. 2, n. 4). Mas una cosa se decía en España y otra se hacía en Filipinas. A pesar de todas las disposiciones del Consejo, el gobernador Juan Niño de Távora entregó a Quesada también la defensa de los sangleyes, alegando que los propios chinos le habían presentado una petición en ese sentido, por ser de más autoridad en su causa el fiscal que otra persona cualquiera ${ }^{39}$.

\section{PRESTIGIO SOCIAL DEL INTÉRPRETE. EL PUESTO, SOLICITADO AL CONSEJO DE INDIAS}

El cargo de intérprete oficial, por consiguiente, pasó a ser considerado un honor y un privilegio, de modo que tuvo muchos pretendientes. Incluso en España. Chinos y japoneses, a su paso por Madrid, pidieron a Felipe III ser nombrados intérpretes

${ }^{38}$ Así lo expresaron por escrito agustinos (25 de julio de 1619) y franciscanos (7 de agosto de 1619) (Filip. 85: 37).

${ }^{39}$ Dio cuenta de ello al rey el 27 de noviembre de 1630 (Filip. 8: r. 1, n.12, $\$ 10$ ). 
en Manila, aunque solicitaron de paso otras gabelas en recompensa a sus servicios. Daré dos ejemplos muy ilustrativos.

\subsection{INTÉRPRETE DE CHINO}

En 1608 andaba por Madrid un chino andariego, cristiano, llamado Antonio Pérez, natural de Macao. Había prestado grandes servicios a Luis Pérez das Mariñas en su frustrado asentamiento en Pinhal, probablemente trayendo y llevando misivas secretas a algunos principales de la ciudad. En tan peligrosos lances había trabado amistad con varios frailes españoles, entre los cuales se hallaba el fogoso dominico Diego Aduarte. Animado sin duda por los religiosos españoles, el chino se decidió a acudir a la corte a pedir una recompensa al monarca, quizá acompañando al padre Aduarte en su viaje a España en 1607:

Tiene suplicado que le haga merçed del offiçio de intérprete de los chinos con vara de alguaçil mayor del alcalde mayor de los dichos chinos y la cárçel d'ellos por su vida y de un hixo, que pueda poner sostituto, si fuere menester, para los despachos de los dichos chinos; el qual officio es neçessario, y le ay siempre que probeen los governadores. Y en esto entiende que sirve a Vuestra Magestad, pues suelen los governadores andar buscando quién ejerça este offiçio con satisfaçión, y no se alla, por ser offiçio sin salario; y ansi- /1v/ -mismo supplico a Vuestra Magestad le mande señalar un salario conpetente o cometer a el governador de las Philipinas que le señale, y hacerle merçed de que el governador le dé una tonelada de repartimiento en las naos del trato de la Nueva Spaña, como veçino qu'es de la çiudad de Manila; y con esta merçed podrá servir a Vuestra Magestad en las ocasiones que se offreçieren, como siempre lo a hecho; que en ello reçivirá merçed. (Filip. 5: n. 57).

La merced pedida, en definitiva, reunía tres cargos en uno: el alguacilazgo y la carcelería del parián, además del puesto de intérprete; pero hay que tener en cuenta que los cargos se juntaban muchas veces: en 1616 Nicolás Chengo era intérprete y alcalde de la cárcel del parián, e intérprete y alguacil fue Francisco Laco (Gil, 2011: 190 y 213). Vista su petición el 19 de junio de 1608, se contestó lacónicamente: «No a lugar» (Filip. 5: n. 72). Pero el chino también sabía el oficio de polvorista, y contaba con el apoyo de dos poderosas órdenes religiosas, la de santo Domingo y la de San Francisco. No sorprende, en consecuencia, que como tal polvorista fuese despachado a Manila con un salario de 400 pesos al año, según ordenó el rey al gobernador don Juan de Silva el 22 de octubre de 1609. Cuando se aprestó la flota de la Nueva España, Antonio Pérez, "yndio natural de la Gran China», se presentó el 7 de junio de 1610 ante los oficiales de la Casa de la Contratación de Sevilla pidiendo pasaje en la nao Santiago, de la que era maestre Santiago de Arrieta. El mismo día, los padres Diego Aduarte, predicador, y Pedro Matías, franciscano, confirmaron la identidad del chino y su origen: era natural de Macao, donde ambos lo habían conocido y tratado. Los dos frailes, que preparaban también ellos su regreso a Filipinas encabezando sendas misiones de religiosos, nos proporcionaron una descripción del solicitante: «Será de hedad de asta veinte e ocho años, de poca barba, lanpiño, color parda, algunas pintas de viruelas en el rostro» (Contrat. 5317: n.2, r. 49). 


\subsection{INTÉRPRETE DE JAPONÉS}

El oidor de México Pedro de Vergara Gaviría envió en 1623 a su hermano Diego de Vergara Gaviría una cama de campo del Japón, con intención de presentar este rico y exótico regalo a Felipe IV. Se dio el caso de que un japonés «pobre y mui humilde», Juan Antonio, que se hallaba en México, se ofreció a llevarla a Madrid y armarla delante del rey, ofrecimiento que causó gran contento al oidor, pues podría reparar el artefacto, en caso de que hubiese sufrido algún desperfecto. En una carta a su hermano, fechada en México el 24 de mayo de 1623, Pedro de Vergara añadió: «Tanbién save este chino [!] adereçar biobos y toda cosa de su tierra que esté maltratada»; buen aviso y excelente golosina para cualquier coleccionista madrileño de curiosidades del Extremo Oriente.

Llegó, en efecto, Juan Antonio a Madrid e hizo entrega al rey de la cama y la armó en su presencia, con gran contentamiento de todos. Pero a continuación sucedió algo con lo que no se contaba. A finales de ese año o principios del siguiente, el japonés pidió al monarca una «ayuda a su nezesidad», dado que era él quien había llevado la cama "de ocho mill y tantas leguas de aquí». Parece, por tanto, a lo que dejan entender estas palabras, que Juan Antonio había transportado la cama desde Manila y que, una vez en México, el oidor Vergara vio el cielo abierto para ganarse el favor del rey con ese presente y se entendió de alguna manera con el nipón para que este acompañase el preciado envío. Fuera como fuese, el 20 de enero de 1624 se remitió la solicitud del palacio del Pardo al Consejo de Indias. Antes de tomar una decisión, el 29 de enero de 1623 el presidente del Consejo, Juan Ruiz de Contreras, recabó más información del hermano del oidor, Diego de Vergara, preguntándole si Pedro de Vergara había dado al japonés algún dinero de la hacienda pública para hacer su viaje a España. La contestación, dada el mismo día, fue tajante: Juan Antonio había venido a España «a sus pretensiones»; la cama le había sido enviada a él, que se había gastado más de 300 reales de su bolsillo en el japonés «solo por contentarle hasta que armasse la cama». De todas maneras, el $1^{\circ}$ de febrero de 1624 se propuso darle una ayuda de 50 ducados en penas de cámara (Filip. 39: n. 21).

Con la característica tenacidad de su raza, Juan Antonio volvió a la carga, presentando meses más tarde la siguiente instancia al Consejo de Indias:

Señor. Juan Antonio, natural del Japón, = dize que su padre y madre y dos hermanos murieron en defensa de la fee cathólica, y él se vino a la Nueva España y estubo dos años en la çiudad de México, de adonde por orden del oydor Don Pedro Gabriel de Gabiria trujo a Vuestra Magestad una cama de campo hecha en el Japón, y la entregó en el Real Palaçio y la armó delante de Vuestra Magestad. = Y porque él es hombre plático en las lenguas de aquellas partes y las sabe muy bien, = Supplica a Vuestra Magestad, en consideraçión de la pérdida de padres y hermanos y gran cantidad de haçienda que les quitaron, le haga merçed de nombrarle por lenguas de la çiudad de Philipinas y la plaça de cónsul, por ser hombre tam plático y que sabrá dar quenta y raçón de todo lo que se le encomendare, que lo reçivirá a particular merçed de la Real mano de Vuestra Magestad. = Y haziéndole Vuestra Magestad esta merçed, supplica se le mande señalar el suelo que se suele dar a los que tienen semejantes offiçios (Filip. 39: n. 23). 
En su sesión del 20 de marzo de 1624, el Consejo decidió: «Que acuda al Gobernador de Filipinas para que le ocupe conforme a su capacidad y talento». Y, efectivamente, el 4 de abril de 1624 el rey expidió la siguiente cédula, dirigida al gobernador de Filipinas:

Don Alonso Fajardo de Tença, caballero de la Orden de Alcántara, mi gobernador y capitán general de las islas Philipinas o a la persona o personas a cuyo cargo fuere el gobierno d'ellas. Juan Antonio, natural del Japón, me a echo relaçión que su padre y madre y dos ermanos suyos murieron en defensa de la fee católica, y él se bino a la Nueba España y estubo dos años en la ciudad de México, y que es plático y sabe muy bien las lenguas de esas partes. Supplicome que, en consideración d'ello, le hiçiese merced de nombrarle por lengua de esa çiudad de Manila y de la plaça de cónsul, señalándole el sueldo que se suele dar a los que tienen semejantes ofiçios. Y abiéndose bisto en mi Consejo real de las Yndias, e tenido por bien de dar la presente, por la qual os mando le ten- /65r/ -gáis por encomendado para ocuparle conforme a su capaçidad y talento, que en ello seré serbido. Fecha en Granada, a quatro de abril de mill y seisçientos y beynte y quatro años. Yo, el rey. Refrendada de Juan Ruiz de Contreras, y señalada de los del Consejo (Indif. 451: libro A8, f. 64v-65r).

No cabe duda de que el hecho de que en la familia de Juan Antonio hubiera cuatro mártires por la fe cristiana pesó en la conciencia del rey y sus ministros. Pero su buena disposición envalentonó al japonés, que tornó a pedir permiso para volver en la flota de la Nueva España sirviendo y llevando ración de soldado, «porque de otra manera no tiene con qué». El Consejo accedió también a esta solicitud, dado que el 22 de marzo se anotó: "que se le da licencia para que vuelva» (Filip. 34: n. 24).

Como bien puede comprenderse, el oficio de intérprete de japonés no se cubrió jamás. La persecución del cristianismo en Japón cortó muy pronto todos los vínculos que se habían establecido entre ambos países. Sorprende la pretensión de ser nombrado cónsul. Había un consulado de mercaderes en México y en Lima, pero no en Manila.

Como hemos visto, los nombramientos de intérpretes normalmente recayeron en personas de importancia. Con el tiempo, por consiguiente, el oficio creó poderosas dinastías. En Manila muchos intérpretes de chino llevaron el apellido Vera (Gil, 2011: 247).

\section{REFERENCIAS BIBLIOGRÁFICAS}

Apol., 1598 = Apología en la cual se responde a diversas calumnias que se escribieron contra los padres de la Compañía de Japón y de la China de Alejandro Valignano (1598). Ed. José Luis ÁlvarezTALADriz, Sophia University, Tokio, 1998.

BN = Biblioteca Nacional de Madrid. Catálogo General de manuscritos, http://catalogo.bne.es/uhtbin/cgisirsi/?ps=HakdcSUMKQ/BNMADRID/31750795/60/108/X.

Col., 1887 = Colección de documentos inéditos relativos al descubrimiento, conquista y organización de las antiguas posesiones españolas de Ultramar. Segunda serie publicada por la Real Academia de la Historia. Tomo núm. 3, II, De las Islas Filipinas. Rivadeneyra, Madrid, 1887. 
Colón, Cristóbal (1992): Textos y documentos completos, ed. C. VARela. Nuevas cartas, ed. J. GiL, Alianza Universidad, Madrid.

Contrat. = Casa de la Contratación. Informaciones y licencias 5217 A a 5536 1534-1790. Archivo General de Indias, Sevilla, 1492-1795.

Filip. = Filipinas. Archivo General de Indias, Sevilla, 1555-1897.

GIL, Juan (2011): Los chinos en Manila. Siglos XVI y XVII, Centro Científico e Cultural de Macau FCT, Lisboa.

Indif. = Indiferente General. Archivo General de Indias, Sevilla, 1492-1870.

Lima $=$ Lima. Archivo General de Indias, Sevilla, 1575-1818.

Méx. = México . Archivo General de Indias, Sevilla, 1519-1823.

Pastells, 1925 = Catálogo de los documentos relativos a las Islas Filipinas existentes en el Archivo de Indias de Sevilla, por Pedro TORReS y LANZAS; precedido de una erudita Historia General de Filipinas por P. Pablo Pastells. Tomos II y III, Compañía General de Tabacos de Filipinas, Barcelona, 1925.

Patron. = Patronato Real . Archivo General de Indias, Sevilla, 1480-1801.

Recop., 1681 = Recopilación de leyes de los reynos de las Indias. 4 tomos (9 libros). Madrid, 1681.

Rel., 1900 = Labor evangélica ministerios apostolicos de los obreros de la Companía de Iesús, fundación, $y$ progressos de su provincia en las islas Filipinas. Nueva ed. ilustrada con copia de notas y documentos para la crítica de la historia general de la soberanía de Espana en Filipinas por el p. Pablo Pastells. I. Heinrich, Barcelona, 1900. 
